\title{
My Departure from the Editor's Chair
}

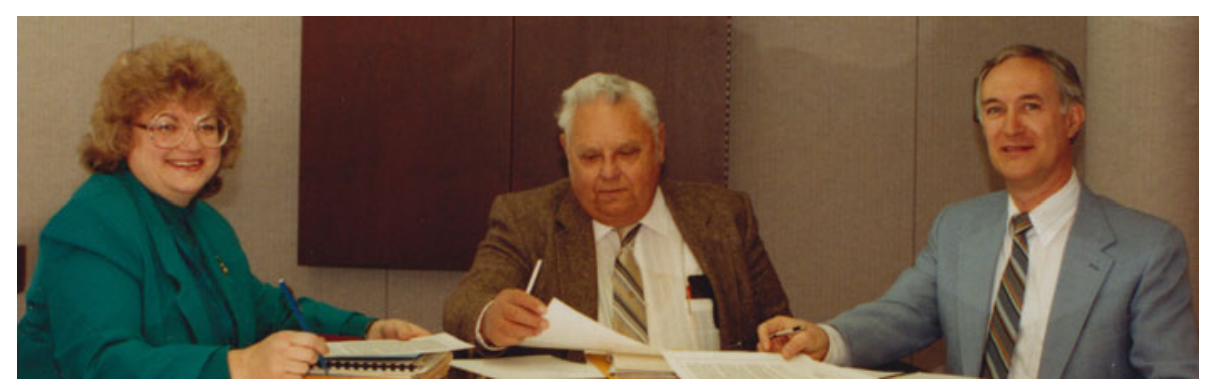

Fig. 11989 Editor's visit to Materials Park. From left, Linda Kacprzak, Jack Smith, and Bill Scott

I will be vacating the position of Editor of the Journal of Phase Equilibria and Diffusion on or about 1 July 2012. I took the position twenty-four years ago after retiring from the Materials Science Department at Iowa State University. The position will be filled by Prof. John Morral, a man whom I have known and respected for over twenty years, and I am confident that he will do an outstanding job. I think it may be of interest to trace the origin of the job.

First, everything that is utilized by man is fabricated from one or another material. Materials Science is therefore concerned with a broad spectrum of materials, and it follows that Materials Science has been and still is closely tied to practicality. With ninety-two elements from which to choose, the number of possible combinations is astronomically large. For binary combinations alone, there are $(92 \times 91) / 2=4186$ possible combinations. Published information concerning the phase relationships in a large fraction of this number were collected, condensed, and published as a compilation by Hansen and Anderko in 1958. Supplements ensued: one by R. P. Elliot in 1965 and another by F. A. Shunk in 1969 (all published by McGraw-Hill).

By the late 1970's a need for a critical evaluation of existing phase equilibria data became evident by the frequent amount and degree of inconsistency in results from different investigations of the same system. This need caused ASM to partner with the Bureau of Standards (now NIST) to organize an Alloy Phase Diagram Program. The first item to be sought was funding, so Ed Langer, then ASM deputy managing director, and ASM Past President William D. Manly, began a nearly year-long travel schedule to visit various industrial companies around the world to seek their support. Though this was a time of stressed economic world health, they were able to raise four million dollars to support the program. The critical reviews were initiated by selecting Category Editors, each of whom was assigned an element whose binary systems were to be critiqued. The effort required to find requisite references for a given binary system and then to acquire access to the actual publications consumed many hours. The order in which the Category Editor worked through the binary systems of his element was left to his discretion. The first critical evaluations began to appear in Vol. 1 of the Bulletin of Alloy Phase Diagrams in 1980, and that was still the title when I became editor in 1988.

Larry Kaufman's book on the computer calculation of phase diagrams was published in 1970 and most of the people who united to form the CALPHAD group attended a symposium in Munster, Germany, in 1972. As with most new approaches, spread was initially slow but increased and expanded with time until today, it is routinely utilized. Computer calculation of phase diagrams began to have a meaningful effect on the manuscripts that the Bulletin received, and in 1991 the Bulletin of Alloy Phase Diagrams became the Journal of Phase Equilibria and acceptable topics were expanded. Again in 2004 it was recognized that while one calculates a phase diagram that has reached its ultimate equilibrium, practicality often requires that utilization be in a metastable condition. This implies a kinetic inhibition to reaching true equilibrium, and a knowledge of diffusivities becomes relevant. Accordingly the journal became in 2004 the Journal of Phase Equilibria and Diffusion.

Now all of this didn't happen by itself. A lot of people were involved, with all being constructive. I am particularly indebted to our Associate Editors. They are a hard working crew who deal directly with the authors of the papers that we publish or reject. They do a fine job, and I'm sure that will continue under John. I should also like to give special thanks to the ladies who have served as a buffer between me and the publishing operation. This runs from Linda Kacprzak, Mary Anne Fleming, Rachel Farrow, Ellyn Vander Kaay, and now to Diane Whitelaw. One and all, they have been patient with me, worried about meeting schedules, and careful to keep all the ducks in their proper row. Lastly I would like to say a word about the people to whom I reported. First there was Nev Pugh at NIST, then at ASM there was Hugh Baker, next Bill Scott, and now Mary Anne Fleming. 
I have found them all to be considerate and constructive. In no case was there any ambiguity in what was expected of me but never any micromanagement. I take away with my departure many pleasant memories of my association with all of these people.

J. F. Smith 